

\section{Second-generation Insulin Analogues - a Review of Recent Real-world Data and Forthcoming Head-to-head Comparisons}

Didac Mauricio ${ }^{1}$ and Irene Hramiak ${ }^{2}$

1. Hospital de Sant Pau, Autonomous University of Barcelona, Barcelona, Spain; 2. Lawson Research Institute, London, ON, Canada

nsulin analogues play a key role in the effective management of type 2 diabetes. However, there are several behavioural barriers to appropriate early initiation of insulin therapy, despite compelling evidence supporting the benefits of this strategy in those patients for whom oral anti-diabetes agents provide insufficient control. The development of second-generation insulin analogues (insulin glargine 300 $\mathrm{U} / \mathrm{mL}$ and insulin degludec) has provided physicians with agents that can provide comparable glycaemic control to first-generation insulin, but with a reduced risk of hypoglycaemia and modes of action suited to once-daily regimens. These characteristics may help overcome patient and physician concerns about early insulin use in disease management. To date, there have been no head-to-head comparisons of second-generation insulins: here we consider recent real-world evidence and the forthcoming direct comparison in the BRIGHT randomised controlled study, as presented at the recent $11^{\text {th }}$ International Conference on Advanced Technologies \& Treatments for Diabetes (ATTD) 2018.

\section{Keywords}

Second-generation, insulin glargine 300, once-daily insulin, hypoglycaemia, type 2 diabetes

Disclosures: Didac Mauricio reports personal fees from Sanofi, Eli Lilly, Merck Sharp \& Dohme, Boehringer Ingelheim, GlaxoSmithKline, Novo Nordisk, Ferrer, Menarini, AstraZeneca and Janssen, outside the submitted work. Irene Hramiak reports grants from Lexicon Pharmaceuticals and Medtronic; grants and personal fees from Sanofi, GlaxoSmithKline, Janssen Pharmaceuticals and Novo Nordisk; personal fees from Amgen Inc, Boehringer Ingelheim, Roche, Insulet Corp and Takeda; grants, personal fees and non-financial support from Astra Zeneca/Bristol-Myers Squibb; and grants, personal fees and other support from Eli Lilly and Merck, outside the submitted work.

Review Process: This supplement did not undergo the journal's standard peer review process but was reviewed by the Editorial Board for scientific accuracy before publication.

Acknowledgements: Editorial assistance was provided by Touch Medical Media and was funded by Sanofi.

Received: 30 April 2018

Published Online: 11 May 2018

Citation: European Endocrinology. 2018;14(Suppl 1):2-9

Open Access Statement: This article is published

under the Creative Commons Attribution Noncommercial

License, which permits any non-commercial

use, distribution, adaptation and reproduction

provided the original author(s) and source are

given appropriate credit. ( ) The Authors 2018.

Corresponding author: Irene Hramiak,

PO Box 5777, Station B, 268 Grosvenor St,

London, Ontario, Canada, N6A 4V2.

E: Irene.Hramiak@sjhc.london.on.ca

Support: The publication of this supplement is

supported by Sanofi. The views and opinions are those

of the authors and not necessarily those of Sanofi.

\section{Second-generation Basal Insulin Analogues in the Management of Type 2 Diabetes}

Didac Mauricio

Hospital de Sant Pau, Autonomous University of Barcelona, Barcelona, Spain

The role of insulin in type 2 diabetes management and challenges to optimal initiation

Type 2 diabetes mellitus (T2DM) is a progressive disease, and many patients eventually require intensification of therapy from oral anti-diabetes agents. Basal insulin therapy is a cornerstone of T2DM management for patients who do not achieve glycaemic control following intensification of oral-therapy regimens. ${ }^{1,2}$ Insulin is an effective option for those with long-standing diabetes, and may be considered as a direct addition to metformin in patients with uncontrolled hyperglycaemia. ${ }^{1-6}$

However, there are psychological and behavioural considerations associated with insulin treatment - from both the perspective of the patient and of the physician - that may result in basal insulin therapy being frequently and inappropriately delayed. ${ }^{7}$ Patients often see insulin therapy as inconvenient, potentially painful, as a treatment of 'last resort' and an indication of failure to manage their disease. ${ }^{2.8}$ Physicians may be reticent to initiate the 'final' option of the recommended stepwise treatment algorithms, and typically share concerns with their patients over weight gain, burden of injections, and an increased risk of hypoglycaemia. $1.2,89$ Indeed, a recent large-scale $(n=40,627)$ real-world study found that the majority of patients did not achieve a target glycated haemoglobin $\left(\mathrm{HbA}_{1 \mathrm{c}}\right.$ ) of $\leq 7 \%$ in the first 3 months or after 2 years, following initiation of basal insulin treatment; the authors noted the role that treatment inertia might play in avoidable, inadequate glycaemic control. ${ }^{10}$ After initiation of basal insulin, delays in escalating titration (i.e. clinical inertia) have also been observed, contributing to suboptimal glycaemic control. ${ }^{11,12}$

\section{Overcoming treatment inertia and appropriate insulin initiation}

Patient concerns should be managed through education, ${ }^{8,13}$ which might include the benefits of glycaemic control, both in the short term and in terms of reduced complications in the longer term, and how appropriate insulin initiation using a personalised treatment approach can help achieve this. 
Physicians should consider that stepwise management algorithms typically wait for a treatment to be ineffective before escalation to, or addition of, another agent. This 'wait for failure' approach often means that patients may not be initiated on insulin therapy for relatively long periods of time, 2,14,15 although current treatment recommendations from the American Diabetes Association and the European Association for the Study of Diabetes highlight that target achievement should be evaluated 3 months after a change of treatment has been made.1,2 Suboptimal glycaemic control arising from treatment inertia has been observed in patients receiving oral anti-diabetes drugs (OADS), with notable delays in treatment escalation and a median of over 7 years before initiation of insulin treatment. ${ }^{15}$ In patients receiving three OADS, the probability of adding an OAD or initiation of insulin was $5.7 \%$ after 1 year (no patients received a fourth $\mathrm{OAD}$ ), and mean $\mathrm{HbA}_{1 \mathrm{c}}$ was $9.7 \%$ at the point of intensification to insulin. ${ }^{15}$

However, there exists compelling evidence to support a more active and target-driven approach, with long-term studies demonstrating the benefits of early target-driven treatment of hyperglycaemia in terms of reducing micro- and macro-vascular complications (Table 1).16,17 Reductions in risk of microvascular disease, myocardial infarction and death achieved with a median of 10 years of intensive glycaemic control ${ }^{16}$ were maintained during 10 years of post-trial follow-up. ${ }^{17}$ Treat-to-target management can be supported with a personalised treatment approach, using timely escalation through step-wise guidelines to achieve tight glycaemic control and reduce unnecessary glycaemic burden resulting from delayed or suboptimal intervention., 2,14,15

\section{Era of the second-generation basal insulin analogue}

In recent years, significant advances have been made in basal insulin therapy. The second generation of basal insulin analogues offers compelling therapeutic benefits over first-generation insulin therapies, which may help physicians and patients overcome some of the barriers to initiation and intensification of insulin treatment. .8-23 $^{12}$

Second-generation basal insulin analogues (insulin glargine $300 \mathrm{U} /$ mL [Gla-300; Sanofi, Paris, France] and insulin degludec [IDeg; Novo Nordisk, Bagsværd, Denmark]) have demonstrated similar efficacy in reducing $\mathrm{HbA}_{1 \mathrm{c}}$ to first-generation insulin therapy (e.g. insulin glargine $100 \mathrm{U} / \mathrm{mL}$ [Gla-100; Sanofi]). ${ }^{18}$ However, the newer agents have longer and more stable pharmacokinetic (PK) and pharmacodynamic (PD) profiles than first-generation treatments. ${ }^{19-23}$ Gla-300 is associated with low within-day variability and high reproducibility (low betweenday variability) in insulin exposure, ${ }^{19,24}$ with predictable and stable glycaemic control well beyond 24 hours. ${ }^{25}$ Similarly, IDeg has demonstrated activity for up to 42 hours with four times lower dayto-day within-patient variability in glucose reduction compared with Gla-100. ${ }^{20}$ A comparison of the steady state PK/PD profiles of Gla300 and IDeg revealed that Gla-300 provided 20\% less within-day fluctuation of metabolic activity than IDeg over 24 hours at a dose of $0.4 \mathrm{U} / \mathrm{kg} /$ day (Figure 1). ${ }^{26}$

These advances have translated into the clinically meaningful benefit of providing similar glycaemic control to Gla-100, but with an ultra-long duration (>24-hour coverage), a more stable PK profile (resulting in reduced glycaemic variability), and greater injection time flexibility. These
Table 1: Long-term* benefits of reducing hyperglycaemia in patients with type 2 diabetes mellitus

\begin{tabular}{|l|l|}
\hline Outcome & $\begin{array}{l}\text { Risk reduction for each 1\% } \\
\text { decrease in } \mathrm{HbA}_{1 \mathrm{c}} \text { over a } \\
\text { median 10-year period }\end{array}$ \\
\hline Death related to diabetes & $21 \%$ \\
\hline All-cause mortality & $14 \%$ \\
\hline Fatal and non-fatal myocardial infarction & $14 \%$ \\
\hline Fatal and non-fatal stroke & $12 \%$ \\
\hline Microvascular endpoints & $37 \%$ \\
\hline Cataract extractions & $19 \%$ \\
\hline $\begin{array}{l}\text { Amputation or death from peripheral vascular } \\
\text { disease }\end{array}$ & $43 \%$ \\
\hline Heart failure & $16 \%$ \\
\hline
\end{tabular}

*Median 10 years. $\mathrm{HbA}_{1 \mathrm{c}}=$ glycated haemoglobin. Information source: Stratton et al., $2000 .^{16}$

Figure 1: Mean glucose infusion rate profiles of insulin glargine $300 \mathrm{U} / \mathrm{mL}$ and insulin degludec at the $0.4 \mathrm{U} / \mathrm{kg} /$ day dose level in steady state

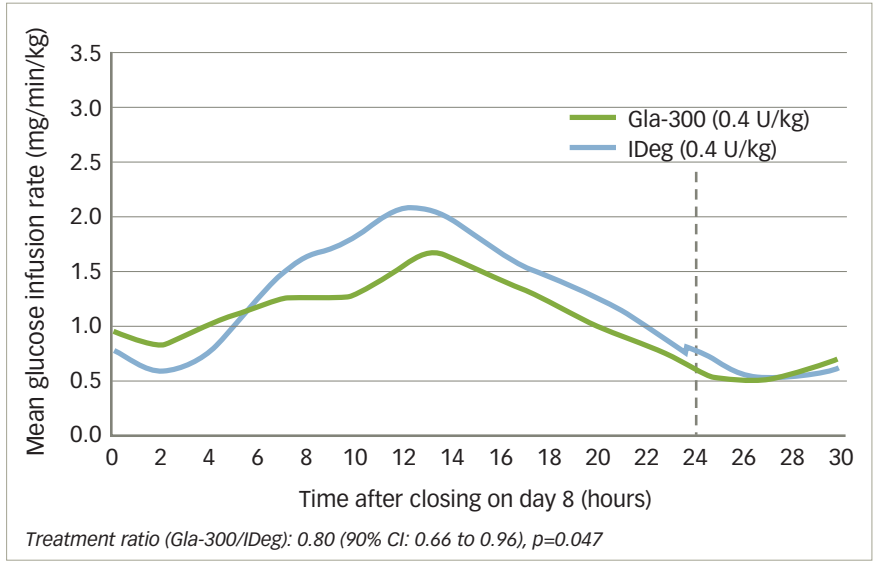

$\mathrm{Cl}=$ confidence interval; Gla-300 = insulin glargine $300 \mathrm{U} / \mathrm{mL} ; \mathrm{IDeg}=$ insulin deg/udec . Reproduced under the CC-BY-NC license from Bailey et al., 2018. ${ }^{26}$

factors make second-generation basal insulin analogues suitable for once-daily treatment. ${ }^{19-23}$

In addition to effectively reducing $\mathrm{HbA}_{1 \mathrm{c}}$, the second-generation basal insulin analogues are associated with a lower risk of hypoglycaemia (both nocturnal hypoglycaemia and also, for Gla-300, all-day hypoglycaemia) compared with Gla-100 (Figure 2). ${ }^{18,27,28}$ For Gla-300, the benefit of lower incidence of hypoglycaemia is especially pronounced in the titration period. ${ }^{29}$

\section{Concluding remarks}

The second-generation basal insulin analogues provide physicians with new treatment options for achieving targeted glycaemic control. While providing similar efficacy in lowering $\mathrm{HbA}_{1 \mathrm{c}}$ to first-generation insulin analogues, the newer insulin treatment options provide additional clinical benefits, including a more stable, ultra-long duration of action that enables once-daily administration with flexibility in daily injection time, together with a lower risk of hypoglycaemia. $\square$ 
Figure 2: Meta-analysis assessment of the risk of nocturnal and anytime hypoglycaemia or severe hypoglycaemia with second-generation insulins compared with insulin glargine $100 \mathrm{U} / \mathrm{mL}$

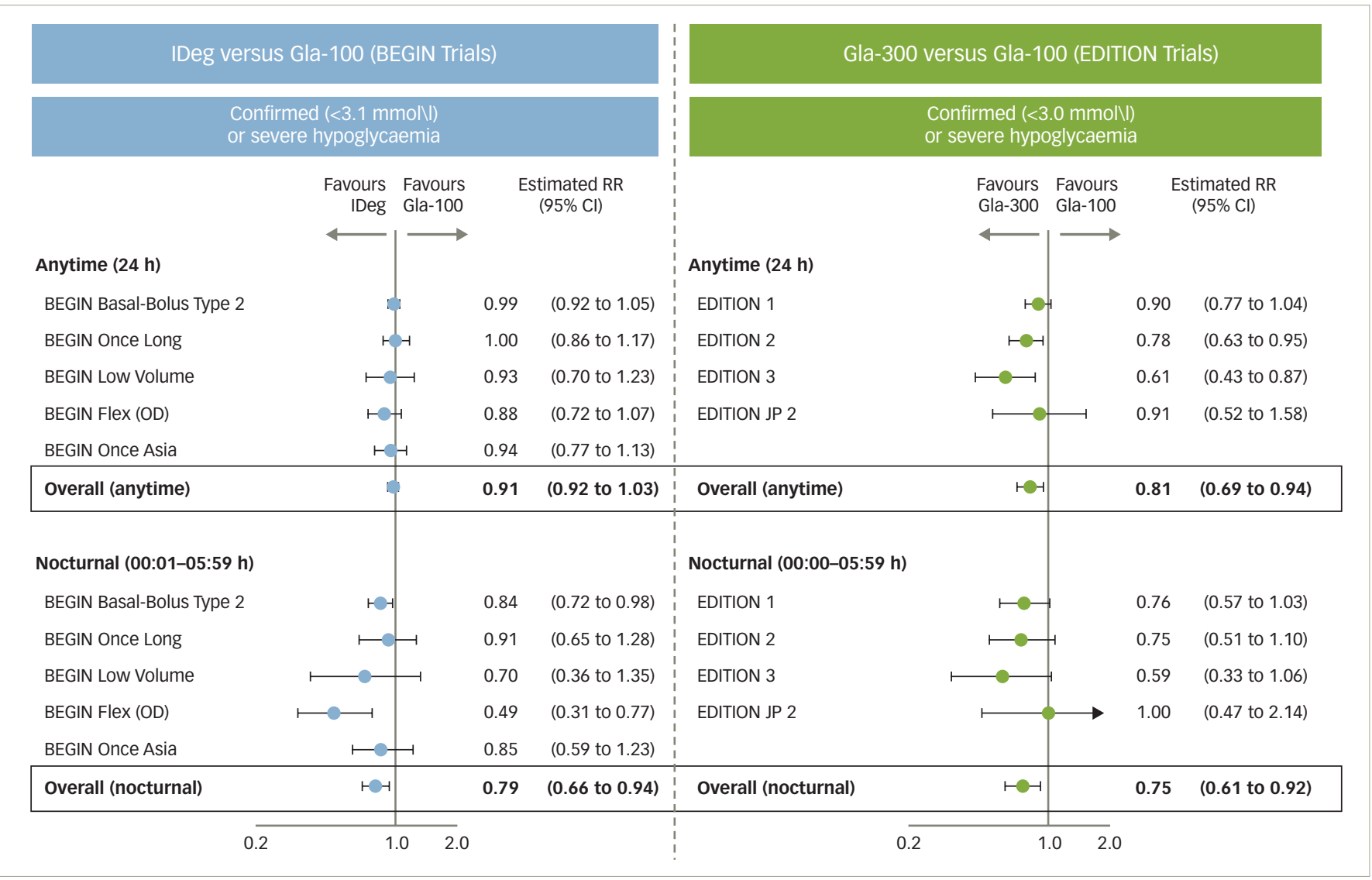

$\mathrm{Cl}=$ confidence interval; Gla-100 = insulin glargine $100 \mathrm{U} / \mathrm{mL}$; Gla-300 = insulin glargine $300 \mathrm{U} / \mathrm{mL} ; \mathrm{h}=$ hours; IDeg = insulin deg/udec; $O D=$ once-daily; $R R=$ relative risk. Reproduced under the CC-BY-NC license from Roussel et al., 2018. ${ }^{18}$

1. Inzucchi SE, Bergenstal RM, Buse JB, et al. Management of hyperglycemia in type 2 diabetes, 2015: a patient-centered

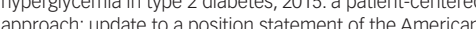
approach: updation a posilion statem a Study of Diabetes. Diabetes Care. 2015;38:140-9.

. Swinnen SG, Hoekstra JB, DeVries JH. Insulin therapy for type 2 diabetes. Diabetes Care. 2009;32 Suppl. 2:S253-9.

3. Fonseca V, Gill J, Zhou R, Leahy J. An analysis of early insulin glargine added to metformin with or without sulfonylurea: impact on glycaemic control and hypoglycaemia. Diabetes Obes Metab. 2011;13:814-22.

4. Gallwitz B, Bretzel RG. How do we continue treatment in patients with type 2 diabetes when therapeutic goals are not reached with oral antidiabetes agents and lifestyle? Incretin versus insulin treatment. Diabetes Care. 2013;36 Suppl. 2:S180-9.

5. Owens DR. Clinical evidence for the earlier initiation of insulin therapy in type 2 diabetes. Diabetes Technol Ther. 2013;15:776-85

6. Forst T, Larbig M, Hohberg C, et al. Adding insulin glargine vs. NPH insulin to metformin results in a more efficient postprandial beta-cell protection in individuals with type 2 diabetes. Diabetes Obes Metab. 2010:12:437-41.

7. Russell-Jones D, Pouwer F, Khunti K. Identification of barriers to insulin therapy and approaches to overcoming them. Diabetes Obes Metab. 2018;20:488-96.

8. Lau AN, Tang T, Halapy H, et al. Initiating insulin in patients with type 2 diabetes. CMAJ. 2012;184:767-76.

9. $\mathrm{Ng} \mathrm{CJ}$, Lai PS, Lee YK, et al. Barriers and facilitators to starting insulin in patients with type 2 diabetes: a systematic review. In J Clin Pract. 2015;69:1050-70

10. Mauricio D, Meneghini L, Seufert J, et al. Glycaemic control and hypoglycaemia burden in patients with type 2 diabetes initiating basal insulin in Europe and the USA. Diabetes Obes Metab. 2017:19:1155-64.

11. Khunti K, Nikolajsen A, Thorsted BL, et al. Clinical inertia with regard to intensifying therapy in people with type 2 diabetes treated with basal insulin. Diabetes Obes Metab. 2016:18:401-9.

12. Mocarski M, Yeaw J, Divino V, et al. Slow Titration and Delayed Intensification of Basal Insulin Among Patients with Type 2 Diabetes. J Manag Care Spec Pharm. 2018;24:390-400.

13. Brod M, Alolga SL, Meneghini L. Barriers to initiating insulin in type 2 diabetes patients: development of a new patient education tool to address myths, misconceptions and clinical realities. Patient. 2014;7:437-50

4. Brown JB, Nichols GA, Perry A. The burden of treatment failure in type 2 diabetes. Diabetes Care. 2004;27:1535-40.

15. Khunti K, Wolden ML, Thorsted BL, et al. Clinical inertia in people with type 2 diabetes: a retrospective cohort study of more than 80,000 people. Diabetes Care. 2013:36:3411-7.

16. Stratton IM, Adler Al, Neil HA, et al. Association of glycaemia with macrovascular and microvascular complications of type 2 diabetes (UKPDS 35): prospective observational study BMH. 2000;321:405-12

17. Holman RR, Paul SK, Bethel MA, et al. 10-year follow-up of intensive glucose control in type 2 diabetes. N Engl I Med. 2008:359:1577-89.

18. Roussel R, Ritzel R, Boëlle-Le Corfec E, et al. Clinical perspectives from the BEGIN and EDITION programmes: Trial-level meta-analyses outcomes with either degludec or glargine $300 \mathrm{U} / \mathrm{ml}$ vs glargine $100 \mathrm{U} / \mathrm{ml}$ in T2DM. Diabetes Metab. 2018; doi: 10.1016/j.diabet.2018.02.002. [Epub ahead of print].

19. Becker RH, Nowotny I, Teichert L, et al. Low within- and between-day variability in exposure to new insulin glargine 300 U/ml. Diabetes Obes Metab. 2015;17:261-7.

20. Haahr H, Heise T. A review of the pharmacological properties of insulin degludec and their clinical relevance. Clin Pharmacokinet. 2014;53:787-800.

21. Owens DR. Pharmacokinetics and pharmacodynamics of insulin glargine $300 \mathrm{U} / \mathrm{mL}$ in the treatment of diabetes and their clinical relevance. Expert Opin Drug Metab Toxicol. 2016;12:977-87.

22. Steinstraesser A, Schmidt R, Bergmann $K$, et al. Investigationa new insulin glargine $300 \mathrm{U} / \mathrm{ml}$ has the same metabolism as insulin glargine $100 \mathrm{U} / \mathrm{mL}$. Diabetes Obes Metab. 2014:16:873-6.

23. Vora J, Cariou B, Evans M, et al. Clinical use of insulin degludec. Diabetes Res Clin Pract. 2015;109:19-31.

24. Bergenstal RM, Bailey TS, Rodbard D, et al. Comparison of Insulin Glargine 300 Units/mL and 100 Units/mL in Adults With Type 1 Diabetes: Continuous Glucose Monitoring Profiles and Variability Using Morning or Evening Injections. Diabetes Care. 2017;40:554-60

25. Becker RH, Dahmen R, Bergmann K, et al. New insulin glargine 300 Units . mL-1 provides a more even activity profile and prolonged glycemic control at steady state compared with insulin glargine 100 Units . mL-1. Diabetes Care. 2015;38: 637-43.

26. Bailey TS, Pettus J, Roussel R, et al. Morning administration of $0.4 \mathrm{U} / \mathrm{kg} /$ day insulin glargine $300 \mathrm{U} / \mathrm{mL}$ provides less fluctuating 24-hour pharmacodynamics and more even pharmacokinetic profiles compared with insulin degludec $100 \mathrm{U} / \mathrm{mL}$ in type 1 profiles compared with insulin degludec 1000

27. Zinman B, Philis-Tsimikas A, Cariou B, et al. Insulin degludec versus insulin glargine in insulin-naive patients with type 2 diabetes: a 1-year, randomized, treat-to-target trial (BEGIN Once Long). Diabetes Care. 2012;35:2464-71

28. Ritzel R, Roussel R, Giaccari A, et al. Better glycaemic control and less hypoglycaemia with insulin glargine $300 \mathrm{U} / \mathrm{mL}$ vs glargine $100 \mathrm{U} / \mathrm{mL}$ : 1-year patient-level meta-analysis of the EDITION clinical studies in people with type 2 diabetes. Diabetes Obes Metab. 2018:20:541-8.

29. Ritzel R, Roussel R, Bolli GB, et al. Patient-level meta-analysis of the EDITION 1, 2 and 3 studies: glycaemic control and hypoglycaemia with new insulin glargine $300 \mathrm{U} / \mathrm{ml}$ versus glargine $100 \mathrm{U} / \mathrm{ml}$ in people with type 2 diabetes. Diabetes Obes Metab. 2015;17:859-67. 


\section{Comparative Efficacy and Safety of Second-generation Basal Insulin Analogues - a Review of Emerging Comparative Data}

Irene Hramiak

Lawson Research Institute, London, ON, Canada

\section{Second-generation basal insulin analogues - the story so far}

Compared with first-generation basal insulin analogues, secondgeneration treatments (insulin glargine $300 \mathrm{U} / \mathrm{mL}$ [Gla-300] and insulin degludec [IDeg]) have demonstrated improved pharmacokinetic (PK) and pharmacodynamic (PD) profiles that provide greater glucose stability (less intra-day variation), together with a lower risk of hypoglycaemia, in patients with type 2 diabetes mellitus (T2DM). ${ }^{1-5}$ As a result, clinicians now have insulin treatment options that provide glycaemic control with the benefit of a stable, ultra-long duration of action that allows once-daily administration with flexibility in daily injection time. However, while the available evidence demonstrates that Gla-300 and IDeg provide similar clinical benefits to first-generation basal insulin analogues (albeit via different mechanisms of action), ${ }^{5-7}$ no direct comparison between the second-generation basal insulin analogues has been presented to date.

\section{Emerging data from the $11^{\text {th }}$ International Conference on Advanced Technologies \& Treatments for Diabetes (ATTD)}

Data from three studies of second-generation basal insulin analogues were presented at ATTD (Vienna, Austria) in February 2018. Real-world evidence from the DELIVER-D study ${ }^{8}$ was validated by a second realworld study, LIGHTNING, ${ }^{\text {w }}$ which used a similar methodology applied to a larger source dataset of electronic medical records. In addition to the real-world studies, the BRIGHT study provides the first randomised controlled trial (RCT) evidence from a head-to-head comparison of second-generation basal insulin analogues. ${ }^{10}$

The most recent data from each of these three studies (DELIVER-D, LIGHTNING, BRIGHT) were presented at the ATTD 2018 meeting and are reviewed here.

\section{Assessing comparative real-world findings in patients switching from first- to second- generation basal insulin analogues \\ DELIVER-D}

Previously published data from the EDITION and BEGIN clinical trials and subsequent meta-analyses have demonstrated consistent efficacy and improved safety profiles for second-generation basal insulin analogues (Gla-300 in EDITION and IDeg in BEGIN), compared with insulin glargine $100 \mathrm{U} / \mathrm{mL}$ (Gla-100)..$^{5-7}$ However, the extent to which these findings from strictly controlled RCT settings are applicable to real-life practice has yet to be examined. In these initial trials, patients with hypoglycaemia were often excluded. . $^{5-7}$ In addition, no direct comparisons between Gla-300 and IDeg have been presented to date.

DELIVER-D was a retrospective, observational study assessing safety and efficacy outcomes from electronic medical records in patients in the US switching from first-generation Gla-100 to either Gla-300 or IDeg. Head-to-head differences between the two second-generation basa insulin analogues were investigated. ${ }^{8}$

DELIVER-D assessed data from the Predictive Health Intelligence Environment database, which covers 39 integrated US healthcare networks. Data were gathered for adult patients with T2DM who were switched from Gla-100 to either Gla-300, IDeg $100 \mathrm{U} / \mathrm{mL}$ or IDeg $200 \mathrm{U} / \mathrm{mL}$ (index date: first prescription date during the period 1st March 2015 to 31st December 2016) and who had at least one Gla-100 prescription within 6 months before the index date (baseline period), but who had not received any other basal insulin prescriptions during this period. In order to be included in the study, patients were required to have electronic medical records for at least 12 months prior to, and at least 6 months following the index date, and to have had at least one glycated haemoglobin $\left(\mathrm{HbA}_{1 \mathrm{C}}\right)$ measurement during the 6-month baseline period. ${ }^{8}$

Patients who switched from Gla-100 to Gla-300 or IDeg were matched in a 1:1 ratio using a propensity score based on: baseline demographics (age, gender, race, insurance type, geographic region); their clinical characteristics 12 months prior to the index date (body mass index, Charlson comorbidity index score, prevalence of comorbidities, concomitant medication use); and their clinical characteristics within the 6-month baseline period $\left(\mathrm{HbA}_{1 c}\right.$, hypoglycaemia incidence, utilisation of all-cause health care). After propensity score matching, the Gla$300(n=810)$ and IDeg $(n=810)$ cohorts were comparable in terms of demographics and baseline characteristics. ${ }^{8}$

The DELIVER-D study included endpoints in both the full matched cohorts and in a subgroup of patients with $\mathrm{HbA}_{1 \mathrm{c}}$ measurements at both the 6-month baseline and during 3-6 months of follow-up. In the matched cohorts, both the incidence of hypoglycaemia (identified by International Classification of Diseases, Ninth Revision, Clinical Modification [ICD-9-CM]/ International Classification of Diseases, $10^{\text {th }}$ Revision, Clinical Modification [ICD-10-CM]) code and/or plasma glucose level $\leq 70 \mathrm{mg} / \mathrm{dL}$ [3.9 mmol/L]) and the event rate (events per patient per year [PPPY], adjusted for baseline hypoglycaemia event) during the 6-month follow-up period were assessed. In the subgroup, the endpoints examined were $\mathrm{HbA}_{1 \mathrm{c}}$ reduction from baseline (closest to index date) at follow-up (latest available value during the follow-up period), and the proportion of patients attaining target $\mathrm{HbA}_{1 \mathrm{c}}{ }^{8}$

Both Gla-300 and IDeg provided similar clinically meaningful decreases in $\mathrm{HbA}_{1 \mathrm{c}}$ following switching $\left(0.49 \%\right.$ and $0.48 \%$ reductions in $\mathrm{HbA}_{1 \mathrm{C}^{\prime}}$ respectively) and enabled similar proportions of patients to achieve the target $\mathrm{HbA}_{1 \mathrm{c}}$ of either $<7.0 \%$ or $<8.0 \%$ (12.9\% versus $15.9 \%$ and $44.2 \%$ versus $44.6 \%$, respectively). Following switching, patients on the secondgeneration treatments experienced a lower incidence of hypoglycaemia versus baseline (Gla-300: 16.5 to $11.9 \%$; IDeg: 15.4 to $12.7 \%$ ); there was no significant difference between Gla-300 and IDeg when adjusted for baseline hypoglycaemia incidence (Figure 1). Both second-generation treatments provided similar reductions in the average number of hypoglycaemia events per year (least squares mean [LSM] difference in event rate -0.01 events/PPPY, 95\% confidence interval [CI] [-0.18, 0.15], p=0.88) and the rate of emergency visits or hospitalisations for hypoglycaemia (LSM difference in event rate -0.01 events/PPPY, 95\% $\mathrm{Cl}[-0.12,0.09], \mathrm{p}=0.82$ ).

Until RCT data are available to support head-to-head comparisons, these data provide valuable insights into real-world outcomes and demonstrate the improved efficacy and safety profiles of modern second-generation basal insulin analogues in routine clinical practice. 


\section{LIGHTNING}

The LIGHTNING study assessed real-world efficacy and safety outcomes in patients with T2DM switching to first- (Gla-100 or insulin detemir [IDet]) or second-generation (Gla-300 or IDeg) basal insulin analogues. Preliminary results of an analysis of Humedica electronic health records - a database capturing data from over 5 million people with diabetes across more than 50 US healthcare systems, 700 hospitals and 7,000 clinics - from 1st April 2015 to 31st December 2016 - are presented here. ${ }^{9}$

The dataset included 779,813 people with T2DM receiving basal insulin analogues. A total of 130,155 basal insulin analogue treatments complied with the study inclusion criteria (Figure 2), representing patients either initiating a new basal insulin or switching between basal insulins. Patients were excluded from the study if they had a likely predominant diagnosis of type 1 diabetes, or if they had more than 10 basal insulin switches within the study window (as such cases would likely represent unusual clinical behaviour).9 Data presented here focus only on findings in patients switching between basal insulin treatment options.

The study approached its assessment using an analysis unit of 'patient treatment' - the period of time between treatment index (basal insulin initiation or switching event) and treatment end - and only counted on-treatment hypoglycaemic events during each patienttreatment unit. Propensity score matching was used to match cohorts for potentially confounding characteristics, allowing for betweentreatment comparison. Key outcomes included the incidence of severe hypoglycaemia and $\mathrm{HbA}_{1 c}$ change from baseline in a subgroup of patients with $\mathrm{HbA}_{1 \mathrm{c}}$ measurements in both time windows. Severe hypoglycaemia was defined as any hypoglycaemic event (ICD-9 or ICD-10 identified or plasma glucose $\leq 70 \mathrm{mg} / \mathrm{dL}$ [3.9 mmol/L]) related to an inpatient or emergency department encounter. $\mathrm{HbA}_{1 \mathrm{c}}$ change was assessed as change from baseline to 76-180 days' follow-up. ${ }^{9}$

Switching from any basal insulin, patients who switched to Gla-300 had a significantly lower incidence of severe hypoglycaemia versus patients switched to the first-generation basal insulin analogues Gla-100 and IDet ( $p=0.009$ and $p=0.002$, respectively). In the direct comparison between second-generation basal insulins, IDeg and Gla-300 provided similar reductions $(p=0.370)$ in the rate of severe hypoglycaemia (Figure 3). ${ }^{9}$

Overall, results of the analysis showed that there was a similar reduction in $\mathrm{HbA}_{1 \mathrm{c}}$ for patients switching to Gla-100, IDet and Gla-300, and similarly there was no significant difference between the second-generation treatments (Gla-300 and IDeg; $\mathrm{p}=0.591$; Figure 4). ${ }^{9}$

Findings from this large, observational study of patients switching from any basal insulin to Gla-100, Gla-300, IDet or IDeg support the conclusions of DELIVER-D: that in real-world populations, second-generation basal insulin analogues provide similar efficacy and improved safety profiles versus first-generation agents. Both second-generation treatments (Gla-300 and IDeg) provided similar reductions in the rate of severe hypoglycaemia during a 6-month follow-up. ${ }^{9}$

\section{DELIVER-D and LIGHTNING - the limitations of real-world studies}

Although these real-world studies provide valuable information about the use of second-generation basal insulins across a broad patient group, there are some limitations to consider. All patient medical records included in DELIVER-D and LIGHTNING came from the US; it would be valuable to also assess the benefits of new basal insulin analogues in
Figure 1: Incidence of hypoglycaemia during 6-month follow-up in DELIVER-D ${ }^{a}$

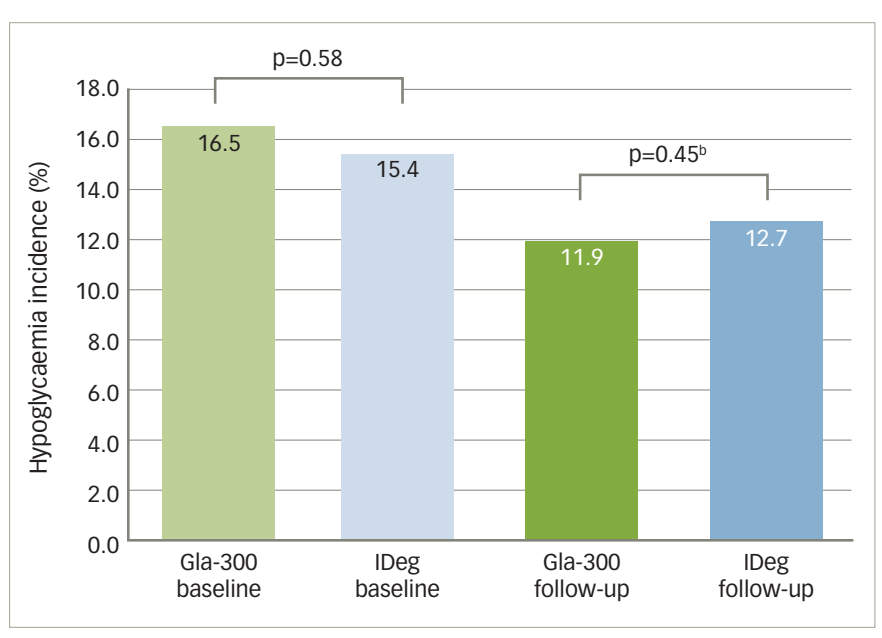

ancidence reduction from baseline to follow-up: Gla-300, $p<0.01$; IDeg, $p=0.05$

${ }^{b}$ Adjusted for baseline hypoglycaemia incidence. Gla-300 = insulin glargine $300 \mathrm{U} / \mathrm{mL}$; IDeg = insulin degludec. Reproduced with permission from: Blonde et al., $2018 .{ }^{8}$

a broader geographical population. Hypoglycaemia incidence was generally generated from hospital administration codes or laboratory glucose values, without data from self-measured blood glucose values or continuous blood glucose monitoring. In addition, there are no insulin titration data from these studies, making it difficult to compare or comment on the dosing regimens in patients switching basal insulin treatment. The follow-up period was relatively short at 6-12 months in the preliminary data presented at the ATTD 2018 meeting. Finally, as with any real-world study, it is difficult to confirm that the prescriptions for the treatments were filled and used appropriately.

\section{The first randomised, controlled head-to-head comparison of second-generation basal insulin analogues \\ BRIGHT}

Recent real-world observations have shown that switching from Gla-100 to either Gla-300 or IDeg resulted in similar improvements in terms of hypoglycaemia risk during the whole follow-up period. Rates of severe hypoglycaemia were similar for the second-generation treatments and significantly lower than first-generation basal insulins, without compromising efficacy in $\mathrm{HbA}_{1 \mathrm{C}}$ reduction.8,9

However, despite the valuable insights obtained from real-world assessments, PK and PD data, and meta-analyses, there has been an absence of RCT head-to-head comparisons of second-generation basal insulin analogues. Such data from randomised controlled studies could help to inform and support optimal treatment selection in T2DM.

The BRIGHT study was a phase IV, 24-week, multinational, multicentre, open-label, two-arm, parallel-group trial (NCT02738151), including insulin-naive adults with T2DM inadequately controlled with oral antihyperglycaemic drugs, with or without a glucagon-like peptide-1 receptor agonist (Figure 5). ${ }^{10}$ Patients were randomised 1:1 to receive Gla-300 $(0.2 \mathrm{U} / \mathrm{kg})$ or IDeg $(10 \mathrm{U})$, administered once-daily using similar treat-totarget titration protocols.

The primary endpoint was $\mathrm{HbA}_{1 \mathrm{c}}$ change from baseline to Week 24; both the non-inferiority and then superiority of Gla-300 versus IDeg were assessed. Secondary endpoints included the incidence and event rates of hypoglycaemia, blood glucose level changes, variability of 
Figure 2: LIGHTNING study population, including inclusion criteria

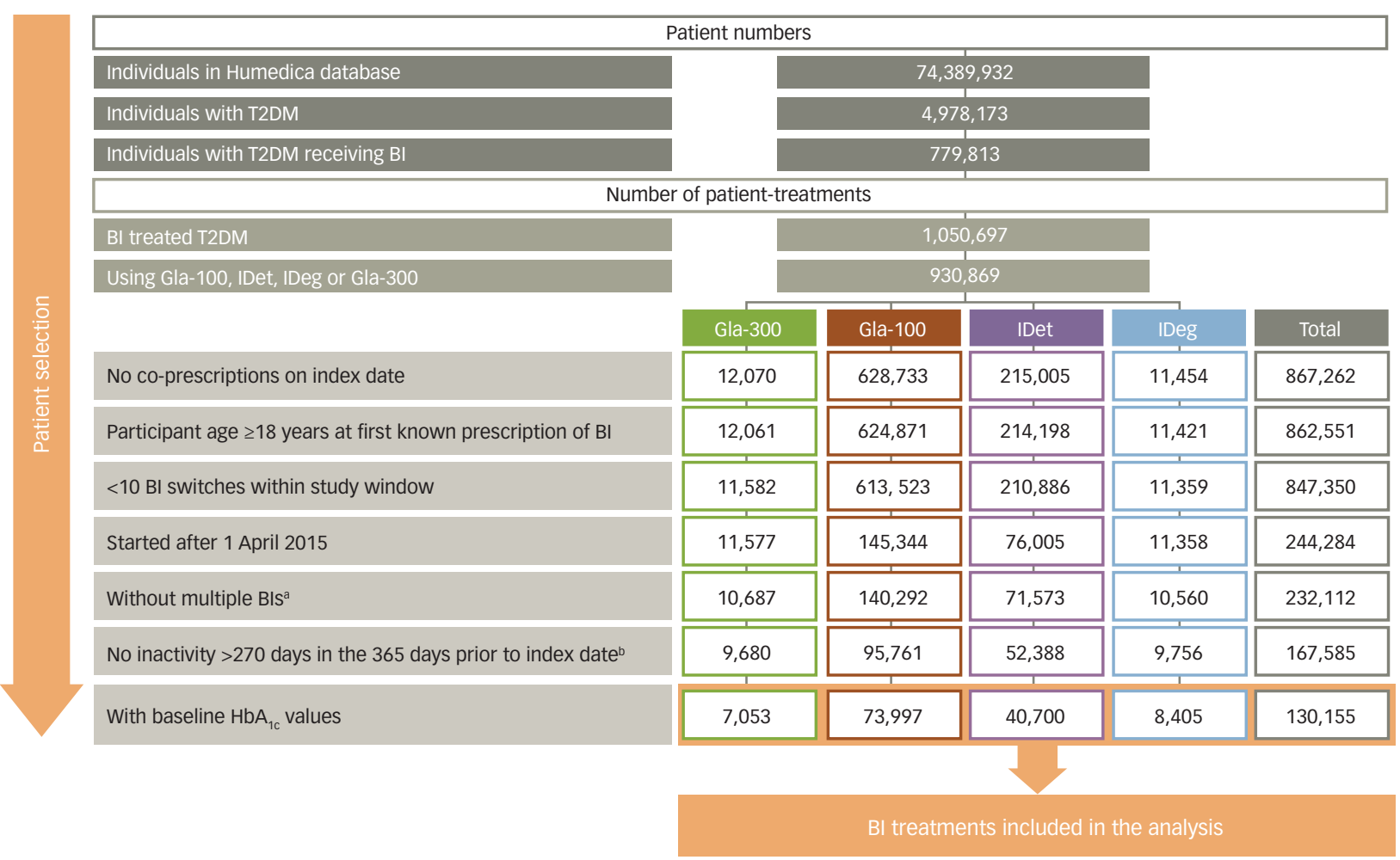

a Multiple treatments defined as those that have another treatment start within 1 week (before or after) of starting the specified basal insulin; binactivity defined as the lack of any time-stamped data. BI = basal insulin; Gla-100 = insulin glargine $100 \mathrm{U} / \mathrm{mL} ; \mathrm{Gla}-300=$ insulin glargine $300 \mathrm{U} / \mathrm{mL} ; \mathrm{HbA}{ }_{1 c}=$ glycated haemoglobin; IDeg = insulin deg/udec; IDet = insulin detemir; T2DM = type 2 diabetes mellitus. Reproduced with permission from: Meneghini et al., 2018.9

Figure 3: Rates of severe hypoglycaemia following a switch to insulin glargine $300 \mathrm{U} / \mathrm{mL}$ compared with a switch to other basal insulin analogues

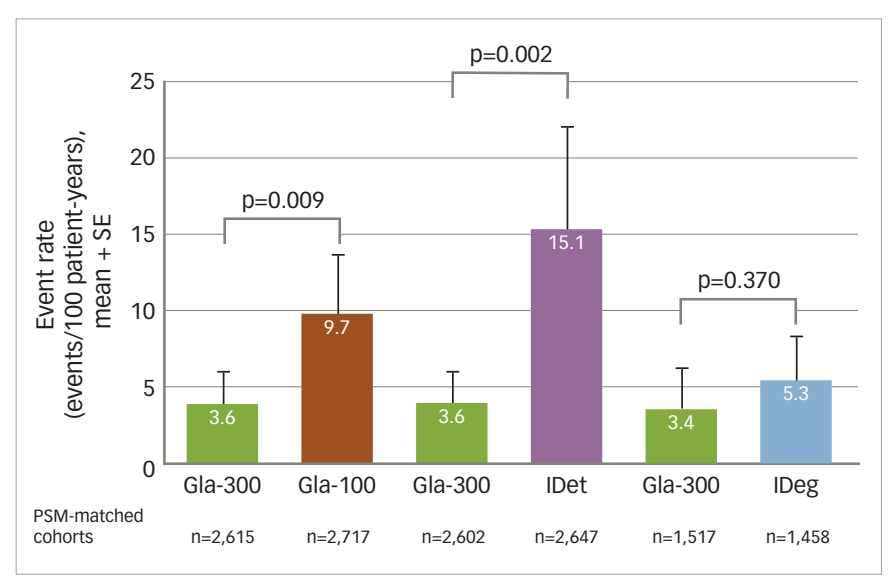

Gla-100 = insulin glargine $100 \mathrm{U} / \mathrm{mL} ;$ Gla-300 = insulin glargine $300 \mathrm{U} / \mathrm{mL} ; \mathrm{IDeg}=$ insulin deg/udec; IDet = insulin detemir; PSM = propensity score matching; $S E$ = standard error. Reproduced with permission from: Meneghini et al. ${ }^{9}$

pre-breakfast glucose and adverse events..$^{10}$ The study also included patient-reported outcomes as assessed by the Diabetes Treatment Satisfaction Questionnaire (DTSQ) and the Hypoglycaemia Attitudes and Behaviour Scale (HABS). ${ }^{11,12}$

At ATTD 2018, study demographics were presented for the BRIGHT study and are summarised here. Overall, 929 participants from 16 countries were randomised to Gla-300 or IDeg and $94 \%$ of participants completed the 24-week treatment period (Figure 6). ${ }^{10}$ Baseline characteristics were well-balanced between the two treatment cohorts, with an average age
Figure 4: $\mathrm{HbA}_{1 \mathrm{c}}$ reduction following a switch to insulin glargine $300 \mathrm{U} / \mathrm{mL}$ compared with a switch to other basal insulin analogues

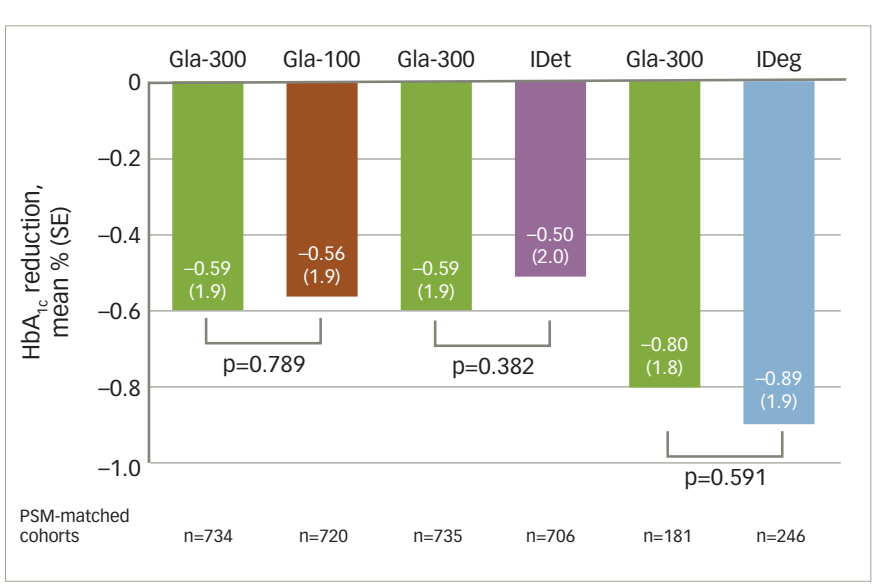

Gla-100 = insulin glargine $100 \mathrm{U} / \mathrm{mL}$; Gla-300 = insulin glargine $300 \mathrm{U} / \mathrm{mL}$;

$\mathrm{HbA}_{1 \mathrm{C}}=$ glycated haemoglobin; IDeg = insulin degludec; IDet = insulin detemir;

$P S M=$ propensity score matching; $S E$ = standard error. Reproduced with permission from: Meneghini et al., $2018 .^{9}$

of 60 years, a baseline $\mathrm{HbA}_{1 \mathrm{c}}$ of $8.6-8.7 \%$ and around half of patients having previously used more than two non-insulin glycaemic control drugs (Table 1). ${ }^{10}$

Both treatment groups used the same weekly insulin titration schedule with a target fasting plasma glucose (self-monitored) of 80-100 mg/ dL (4.4-5.6 mmol/L) without hypoglycaemia. The preliminary study data suggest a successful titration, with $47 \%$ of participants having reached the target $\mathrm{HbA}_{1 \mathrm{c}}$ of $<7.0 \%$ using a starting dose of $0.19 \mathrm{U} / \mathrm{kg}$ for Gla-300 and $0.12 \mathrm{U} / \mathrm{kg}$ for IDeg, as per label instructions. No specific 
Figure 5: BRIGHT study design and inclusion criteria

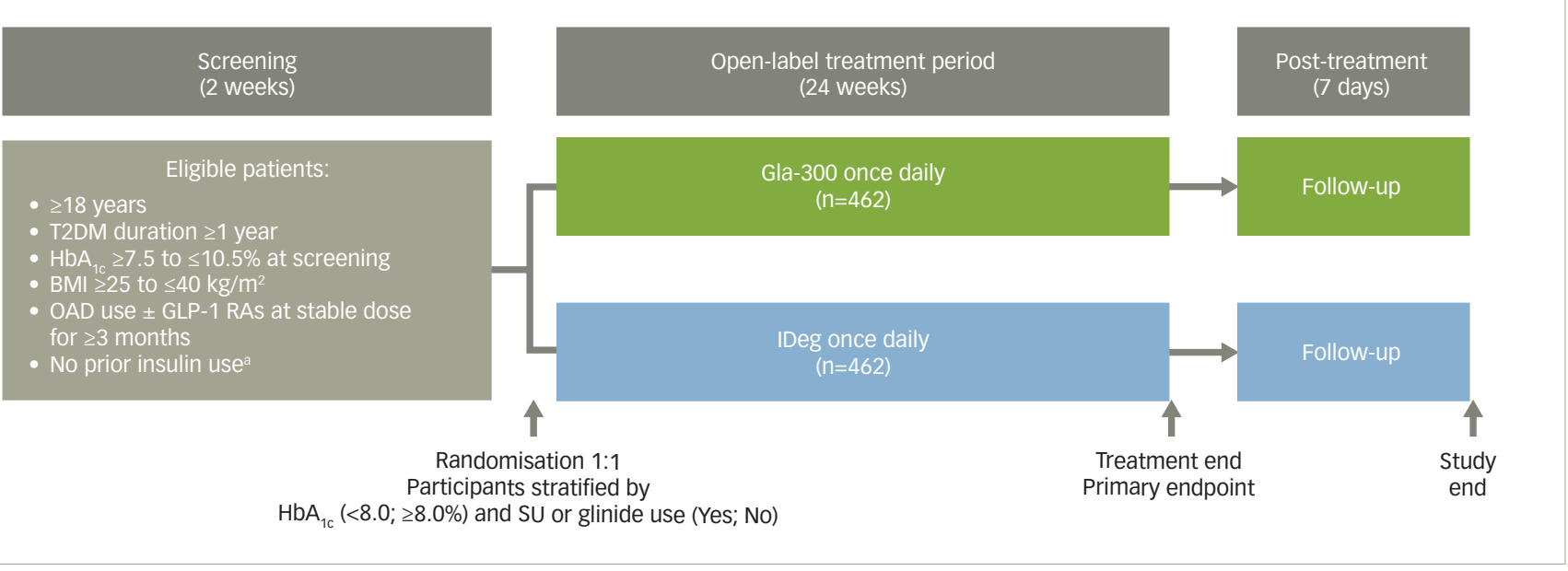

a With the exception of a maximum of 8 consecutive days or 15 days total prior insulin use. BMI = body mass index; Gla-300 =insulin glargine 300 U/mL; IDeg = insulin deg/udec; GLP-1 RA = glucagon-like peptide-1 receptor agonist; $H H_{1 C}=$ glycated haemoglobin; OAD = oral antihyperglycemic drug; $S U=$ sulfonylureas; $T 2 D M=$ type 2 diabetes mellitus. Reproduced with permission from: Cheng et al., 2018. ${ }^{10}$

Figure 6: Patient randomisation in the BRIGHT study and overall completion data

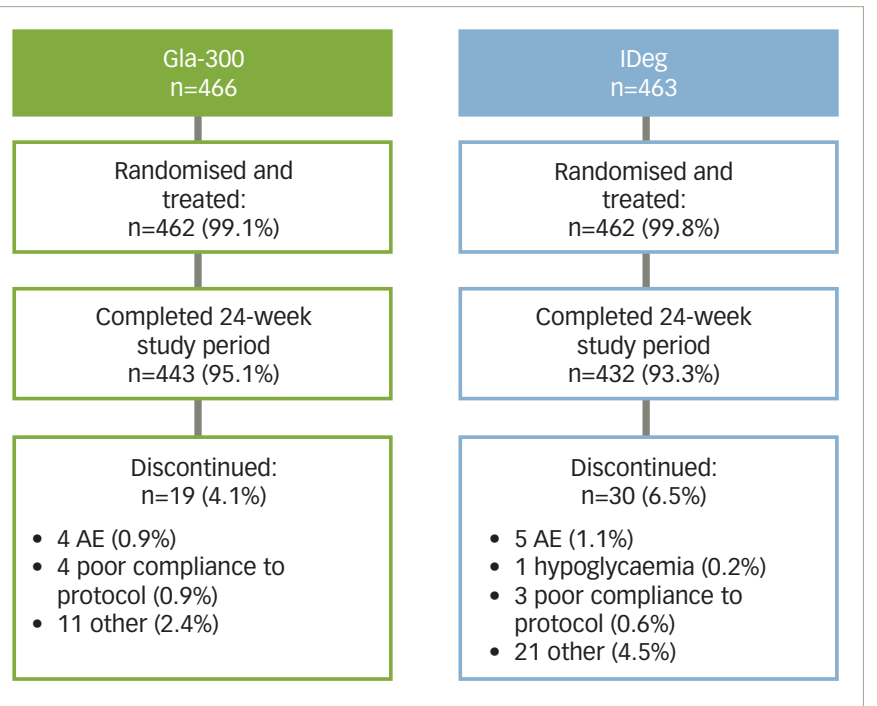

$A E=$ adverse event; Gla-300 = insulin glargine $300 \mathrm{U} / \mathrm{mL} ; \mathrm{IDeg}=$ insulin deg/udec. Reproduced with permission from: Cheng et al., 2018.10

safety concerns were noted (Table 2). A similar proportion of patients in each treatment arm experienced treatment-related adverse events, with few serious events (less than $5 \%$ in each arm) and only around $1 \%$ of patients discontinuing treatment because of adverse effects. ${ }^{10}$

We await with interest further details on results from the BRIGHT study, comparing second-generation insulins in a head-to-head context.

\section{Discussion}

With the availability of second-generation basal insulin analogues, clinicians now have ultra-long acting, efficacious treatment options with a low associated risk of hypoglycaemia.

Selection of a treatment for the personalised management of diabetes should be supported by data in relevant patient populations: here we have discussed both real-world data and clinical observations to supplement existing evidence from phase III RCTs and meta-analyses for Gla-300.
Table 1: BRIGHT study patient demographics

\begin{tabular}{|l|l|l|}
\hline & $\begin{array}{l}\text { Gla-300 } \\
(\mathrm{n}=466)\end{array}$ & $\begin{array}{l}\text { IDeg } \\
(\mathrm{n}=463)\end{array}$ \\
\hline Age, years & $60.6 \pm 9.6$ & $60.5 \pm 9.8$ \\
\hline Sex (male/female), $\mathrm{n}(\%)$ & $247 / 219(53.0 / 47.0)$ & $252 / 211(54.4 / 45.6)$ \\
\hline BMl, kg/m² & $31.7 \pm 4.3$ & $31.3 \pm 4.4$ \\
\hline HbA $_{1 c^{\prime}} \%$ & $8.71 \pm 0.83$ & $8.57 \pm 0.80$ \\
\hline Known T2DM duration, years & $10.5 \pm 6.1$ & $10.7 \pm 6.5$ \\
\hline $\begin{array}{l}\text { Number of prior non-insulin } \\
\text { antihyperglycemic treatments }\end{array}$ & & \\
\hline $\begin{array}{c}\text { used, } \mathrm{n} \text { (\%) } \\
0\end{array}$ & $0(0.0)$ & $1(0.2)$ \\
\hline $\begin{array}{l}1 \\
\text { > } 2\end{array}$ & $70(15.0)$ & $65(14.0)$ \\
$179(38.4)$ & $187(40.4)$ \\
\hline
\end{tabular}

Randomised population. Data expressed as mean \pm SD unless stated otherwise. $\mathrm{BMI}=$ body mass index; Gla-300 = insulin glargine $300 \mathrm{U} / \mathrm{mL} ; \mathrm{HbA}_{1 \mathrm{r}}=$ glycated haemoglobin; IDeg = insulin deg/udec; $S D$ = standard deviation; T2DM = type 2 diabetes mellitus. Reproduced with permission from: Cheng et al., 2018.10

Table 2: Preliminary safety data from the BRIGHT study

\begin{tabular}{|l|l|l|}
\hline n (\%) & $\begin{array}{l}\text { Gla-300 } \\
(n=462)\end{array}$ & $\begin{array}{l}\text { IDeg } \\
(n=462)\end{array}$ \\
\hline Participants with any TEAE & $202(43.7)$ & $221(47.8)$ \\
\hline Participants with any TE SAE & $21(4.5)$ & $20(4.3)$ \\
\hline Participants with any TEAE leading to death & $1(0.2)$ & $0(0.0)$ \\
\hline $\begin{array}{l}\text { Participants with any TEAE leading to } \\
\text { permanent treatment discontinuation }\end{array}$ & $4(0.9)$ & $5(1.1)$ \\
\hline
\end{tabular}

Gla-300 = insulin glargine $300 \mathrm{U} / \mathrm{mL} ;$ IDeg = insulin deg/udec; SAE = serious adverse event; TE = treatment-emergent; TEAE = treatment-emergent adverse event. Reproduced with permission from: Cheng et al., 2018.10

DELIVER-D demonstrated that switching from Gla-100 to Gla-300 or IDeg provides similar glucose-lowering efficacy and reductions in hypoglycaemia risk between the second-generation insulins. LIGHTNING supported these findings, reporting a similar incidence of severe hypoglycaemia for Gla300 and IDeg, but lower than first-generation basal insulins, while retaining efficacy in $\mathrm{HbA}_{1 \mathrm{c}}$ reduction. 
Early demographic data from the head-to-head BRIGHT study show that it is well positioned, in terms of patient selection, randomisation and appropriate titration, to deliver meaningful insights into T2DM treatment selection when further data are released.
Together, data from both RCTs and real-world studies provide physicians with robust evidence for the clinical benefits of second-generation basal insulin analogues and support informed decisions when initiating and intensifying basal insulin therapy. $\square$
1. Bailey TS, Pettus J, Roussel R, et al. Morning administration of $0.4 \mathrm{U} / \mathrm{kg} /$ day insulin glargine $300 \mathrm{U} / \mathrm{mL}$ provides less fluctuating 24-hour pharmacodynamics and more even pharmacokinetic profiles compared with insulin degludec
diabetes. Diabetes Metab. 2018;44:15-21.

2. Haahr H, Heise T. A review of the pharmacological properties of insulin degludec and their clinical relevance. Clin Pharmacokinet. 2014;53:787-800.

3. Owens DR. Pharmacokinetics and pharmacodynamics of insulin glargine $300 \mathrm{U} / \mathrm{mL}$ in the treatment of diabetes and their clinical relevance. Expert Opin Drug Metab Toxicol. 2016;12:977-87

4. Vora J, Cariou B, Evans M, et al. Clinical use of insulin degludec. Diabetes Res Clin Pract. 2015;109:19-31.

5. Ritzel R, Roussel R, Bolli GB, et al. Patient-level meta-analysis of the EDITION 1, 2 and 3 studies: glycaemic control and of the EDITION 1, 2 and 3 studies: glycaemic control and hypoglycaemia with new insulin glargine $300 \mathrm{U} / \mathrm{ml}$ versus
glargine $100 \mathrm{U} / \mathrm{ml}$ in people with type 2 diabetes. Diabetes glargine $100 \mathrm{U} / \mathrm{ml}$ in people w/h
Obes Metab. 2015;17:859-67.

6. Russell-Jones D, Gall MA, Niemeyer M, et al. Insulin degludec results in lower rates of nocturnal hypoglycaemia and fasting plasma glucose vs. insulin glargine: A meta-analysis of seven clinical trials. Nutr Metab Cardiovasc Dis. 2015;25:898-905

7. White JR, Jr. Advances in Insulin Therapy: A Review of New Insulin Glargine 300 Units $/ \mathrm{mL}$ in the Management of Diabetes. Clin Diabetes. 2016;34:86-91.

8. Blonde L, Zhou FL, Bosnyak Z, et al. Real-world evidence demonstrates comparable clinical outcomes of switching from insulin glargine $100 \mathrm{U} / \mathrm{mL}$ (Gla-100) to insulin glargine $300 \mathrm{U} / \mathrm{mL}$ (Gla-300) vs insulin degludec (IDeg) in patients with type 2 diabetes (T2D). Presented at the 11th International Conference on Advanced Technologies \& Treatments for Diabetes Vienna, Austria, 14-17 February 2018. Abstr ATTD8-0427.

9. Meneghini L, Zhou FL, Bosnyak Z, et al. Hypoglycemia risk associated with basal insulin use in type 2 diabetes (T2DM) associated winh basal insulin use in type 2 diabotes (I2DM): the LIGHTNING study. Presented at the 11th International Diabetes, Vienna, Austria, 14-17 February 2018. Abstr ATTD80420.
10. Cheng A, Rosenstock J, Ritzel R, et al. Efficacy and safety of insulin glargine- $300 \mathrm{U} / \mathrm{mL}$ vs insulin degludec-100 U/ $\mathrm{mL}$ in insulin-naive adults with T2DM: first head-to-head randomised clinical trial, Presented at the 11th International Conference on Advanced Technologies \& Treatments fo Diabetes, Vienna, Austria, 14-17 February 2018. Abstr ATTD8-0440.

11. Zhou FL, Ye F, Berhanu P, et al. Real-world evidence concerning clinical and economic outcomes of switching to insulin glargine $300 \mathrm{units} / \mathrm{mL}$ vs other basal insulins in patients with type 2 diabetes using basal insulin. Diabetes Obes Metab. 2018;20:1293-7.

12. Bradley C, The Diabetes Treatment Satisfaction Questionnaire: DTSQ. In: Bradley C (ed). Handbook of Psychology and Diabetes: a guide to psychological measurement in diabetes Diabetes: a guide to psychological measurement in diabetes
research and practice, Chur: Harwood Academic Publishers, 1994:111-32.

13. Polonsky WH, Fisher L, Hessler D, Edelman SV. Identifying the worries and concerns about hypoglycemia in adults with type 2 diabetes. I Diabetes Complications. 2015;29:1171-6. 


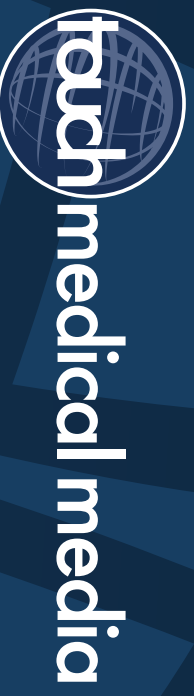

The White House

Mill Road

Goring-On-Thames

RG8 9DD

UK

T: +44 (0) 2071935482

E: info@touchmedicalmedia.com

www.touchENDOCRINOLOGY.com 